\section{$\underset{\substack{\text { hommes } \\ \text { \& migrations }}}{ }$}

\section{Hommes \& migrations}

Revue française de référence sur les dynamiques

migratoires

$1326 \mid 2019$

Londres et ses migrations

\title{
Sistermatic, une boîte de nuit pour lesbiennes et queers noires
}

\section{Martin Evans}

\section{OpenEdition \\ Journals}

Édition électronique

URL : https://journals.openedition.org/hommesmigrations/9757

DOI : 10.4000/hommesmigrations.9757

ISSN : 2262-3353

Éditeur

Musée national de l'histoire de l'immigration

Édition imprimée

Date de publication : 1 juillet 2019

Pagination : 84-85

ISBN : 978-2-919040-46-9

ISSN : $1142-852 X$

Référence électronique

Martin Evans, "Sistermatic, une boîte de nuit pour lesbiennes et queers noires », Hommes \& migrations [En ligne], 1326 | 2019, mis en ligne le 01 janvier 2019, consulté le 16 janvier 2022. URL : http:// journals.openedition.org/hommesmigrations/9757 ; DOI : https://doi.org/10.4000/ hommesmigrations.9757 


\section{Sistermatic, une boîte de nuit pour lesbiennes et queers noires}

\section{Martin Evans,}

professeur d'histoire moderne européenne, président du comité directeur du Centre Middle East and North Africa à l'université du Sussex.

Fondé en 1986 par Yvonne Taylor, Lorna Edwards, Sharon Lee et Eddie Lockhart, Sistermatic était un collectif londonien de lesbiennes noires, de DJ et de férues de musique. Elles voulaient créer une boîte de nuit de femmes pour lesbiennes et femmes queer, tenue par des femmes de couleur et leurs amies - un lieu musical encore inexistant à l'époque dans le monde des boîtes de nuit londoniennes.

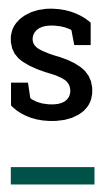

istermatic fut basé sur le principe afro-caribéen «Shubeen», à savoir des espaces accueillants, mis en place par les communautés afro-caribéennes, où tous pouvaient danser, se détendre et s'exprimer sans craindre le racisme. Cependant, Sistermatic se voulait aussi un lieu de joie et d'émancipation, loin du racisme et de l'homophobie présents dans d'autres lieux et d'autres événements, un lieu où toutes les femmes seraient les bienvenues. Grâce à la musique, Sistermatic a ainsi réussi à rassembler des femmes à une période où la communauté noire homosexuelle de Londres était fréquemment attaquée, aussi bien dans la vie quotidienne que par les médias et les discours politiques. Entre 1986 et le début des années 1990, le collectif Sistermatic jouait régulièrement au South London Women's Centre et dans des manifestations féministes du tout Londres.

\section{Témoignage de Glynnis}

«Faire son coming out dans la région de Midlands au milieu des années 1980 était une expérience très difficile à affronter. J'avais une vie sociale très active dans la communauté caribéenne, j'allais à des soirées dansantes, à des fêtes entre amis où je pouvais écouter de la musique et danser sur du reggae, du dance hall, du calypso, du blues, de la soul et $d u R^{\prime} n$ 'B. En revanche, quand j'ai fait mon coming out, je ne me sentais plus à ma place nulle part. La communauté noire hétérosexuelle ne savait pas comment se comporter, ne voulait pas accepter ou être à l'aise avec ma sexualité, ce qui rendit difficile pour moi de me sentir bien aux événements auxquels j'avais l'habitude d'aller. C'était aussi difficile de se sentir intégrée à la communauté gay puisqu'il n'y avait seulement que quelques femmes noires lesbiennes 
sur la scène gay dans les Midlands. La musique n'était pas vraiment à mon goût et il m'était difficile de m'identifier à ce qui était proposé.

"J'ai commencé à descendre en voiture sur Londres à lafin des années 1980 pour aller dans des clubs gays. On m'a ensuite fait connaître le South London Women's Centre qui était fréquenté par des femmes noires et d'autres couleurs, mais aussi des femmes noires comme DJ. Sistermatic savait comment organiser des fêtes géniales! À l'époque, c'était le seul endroit qui passait le genre de musiques qui me plaisait et où je pouvais m'identifier aux DJ et à la foule... Cela a eu un impact considérable sur ma propre estime et sur la construction de mon identité en tant que femme noire et homosexuelle. Cet endroit m'a donné, comme à beaucoup de mes amies, le sentiment d'appartenir à un collectif et un lieu que l'on pouvait considérer comme le nôtre.»

\section{Les musiques reggae fréquemment jouées à Sistermatic:}

«Gal Wine», Chaka Demus and Pliers. « Night Nurse», Gregory Isaacs. «Substitute Lover», Half Pint. "If Love So Nice», Junior Kelly. «To the Foundation », Dennis Brown. «My Conversation», The Uniques. «Sweetness», Beres Hammond. «Black Pride», Kofi. «Queen Majesty», Techniques. 